\title{
CONCEPÇÕES DE ENSINO DE CIÊNCIAS NO INÍCIO DO SÉCULO XX: O OLHAR DO EDUCADOR ALEMÃO GEORG KERSCHENSTEINER
}

\author{
Conception of the teaching of sciences \\ in the early twentieth century: the view of the German \\ educator Georg Kerschensteiner
}

\author{
Giuliana Maria Gabancho Barrenechea Bueno ${ }^{1}$. Sidilene Aquino \\ de Farias $^{2}$. Luiz Henrique Ferreira ${ }^{3}$
}

\begin{abstract}
Resumo: Neste artigo, investigamos as concepções de ensino de ciências no limiar do século XX, mediante a visão de um teórico do movimento escolanovista na Europa, o alemão Kerschensteiner, que investigou e discutiu sobre a problemática do ensino a partir de sua prática pedagógica. Para tanto, buscou-se analisar as principais concepções acerca do ensino de ciências presentes na obra do referido autor, intitulada "Essência e valor do ensino scientifico-natural". Tomamos como contexto da análise o cenário sócio-econômico e político no qual o processo educativo estaria inserido no referido período, como forma de compreender a contribuição que o teórico trouxe para o entendimento da importância do ensino como um todo na formação do ser humano. A diversidade de idéias sobre educação defendidas pelo autor possibilitou importantes reflexões acerca da participação do aluno como sujeito ativo no processo de ensino-aprendizagem no ensino de ciências.
\end{abstract}

Palavras-chave: Ensino de Ciências. Escola Nova. Georg Kerschensteiner.

Abstract: In this article, we investigate the conceptions of education in the sciences at the threshold of the $20^{\text {th }}$ century, by means of the vision of a theoretician of the New School movement in Europe, the German Kerscheinsteiner, who investigated and argued for teaching from his pedagogical practice. For this, it we tried to analyze the main conceptions concerning the teaching of sciences present in the work of the author, entitled "Essence and value of scientific-natural education". Taking as the context of the analysis, the social-economic and political factors in which the educational process would be inserted in the related period, as a means to understanding the contribution that the theoretician brought for the understanding of the importance of teaching as a whole in the formation of the human being. The diversity of ideas on education, defended by the author, made possible important reflections concerning the participation of the pupil as an active subject in the process of teaching learning in the sciences.

Keywords: Science Teaching. Education. New School.

\footnotetext{
${ }^{*}$ Em citações literais referentes à obra do pedagogo Kerschensteiner, mantivemos a grafia da língua portuguesa presente na publicação, que data do início do século XX.

${ }^{1}$ Laboratório de Ensino e Aprendizagem em Química, Centro de Ciências Exatas e de Tecnologia, Universidade Federal de São Carlos. Rodovia Washington Luís, km 235, SP-310. São Carlos, SP, Brasil. 18.052-780. ferreira@ufscar.br

${ }^{2}$ Departamento de Química, Instituto de Ciências Exatas, Universidade Federal do Amazonas (UFAM).

Manaus, AM, Brasil.

${ }^{3}$ Departamento de Química, Centro de Ciências Exatas e de Tecnologia, Universidade Federal de São Carlos. São Carlos, SP, Brasil.
} 


\section{Introdução}

Tanto no contexto educacional brasileiro quanto internacional, a partir da segunda metade do século passado, o ensino de ciências passou a ser foco de estudos sob diversos aspectos: concepções epistemológicas, valores educacionais associados, livro didático, formação do professor, o papel da experimentação e ensino-aprendizagem de conceitos científicos, entre outros. Diversos investigadores educacionais têm discutido e apontado, em seus estudos, metodologias alternativas que visam à melhoria da qualidade deste ensino (HODSON, 1988; DRIVER et al., 1999; MORTIMER; SCOTT, 2002).

Entretanto, questões que envolvem a preocupação de por que ensinar, o que ensinar e como ensinar ciências, entre outras pertinentes nas escolas de Educação Básica, não são recentes no cenário educacional internacional. Neste texto, procuramos discutir estas questões sob o olhar do pedagogo alemão Georg Kerschensteiner. É importante ressaltar que as ideias deste educador surgiram no período de transição entre o século XIX e XX, momento em que estavam sendo formuladas grandes mudanças no cenário educacional e no qual surgiu uma nova proposta pedagógica em oposição ao ensino tradicional, denominada "Escola Nova". Tal corrente pedagógica tinha suas ideias disseminadas mais fortemente na América do Norte e no ocidente Europeu. Nesse contexto, as concepções do pedagogo relacionadas ao processo educativo, que visavam atender as demandas sociais do referido período na Alemanha, eram pautadas na nova pedagogia.

Assim, buscaram-se conhecer as concepções, reflexões e alternativas, realizadas por esse educador, relacionadas ao Ensino de Ciências, uma vez que, durante sua trajetória, ele estruturou uma escola pensada na formação educacional para o homem daquele período. Acredita-se que o estudo sobre a concepção do ensino de ciências na visão do educador possa contribuir para a compreensão da educação no Brasil.

Além da concepção de Ensino de Ciências, no decorrer deste texto serão expostas outras ideias do pedagogo acerca da prática educativa, visto que, ao longo de sua vida, ele empreendeu projetos escolares que tinham a finalidade de formar e preparar o cidadão desde o período inicial - educação infantil - até a adolescência. Essa abordagem objetiva proporcionar uma visão mais ampla do contexto em que tal educação estava inserida no referido período, e, ainda, visa elucidar as ideias desenvolvidas pelo pedagogo que podem contribuir para uma melhor compreensão acerca da educação e o ensino de ciências de nossos dias, pois entende-se ser este um tema atual que reflete a preocupação dos educadores e da sociedade brasileira.

Diante do exposto, cumpre destacar que o texto está dividido em três partes: inicialmente, é abordado o contexto socioeconômico no qual as ideias do pedagogo foram produzidas, pois estes fatores influenciam o processo educativo, configurando-se como agentes determinantes das aspirações sociais referentes à educação e atribuindo, desta maneira, uma função social à escola; em seguida, apresenta-se uma breve biografia e as principais concepções do educador num contexto educacional amplo, e, por fim, são abordadas as principais concepções presentes na obra do pedagogo, intitulada "Essência e valor do ensino scientifico-natural". Nesta última parte, busca-se a compreensão da atualidade das ideias de Kerschensteiner, e as similaridades com os atuais estudos sobre Ensino de Ciências, entendendo a existência de prováveis limitações, visto que o contexto que vivenciamos, hoje, diante das grandes transfor- 
mações que a sociedade sofreu nas últimas décadas, tem uma dinâmica completamente diferente daquele em que as ideias do pedagogo foram produzidas.

\section{Principais influências no processo educativo no limiar do século XX}

Discutir sobre educação não é algo novo, pois diversos estudos desenvolvidos por filósofos, sociólogos, psicólogos e pedagogos de épocas anteriores, como Platão, Rousseau, Kant, Durkeim, ou mais recentes, como Dewey, Paulo Freire, Edgar Morin, apontam para a necessidade de uma discussão constante acerca de tudo o que esta relacionado à questão educacional.

Desde o século XVIII, algumas teorias educativas são apresentadas com o intuito de apontar um modelo "correto" de educação que atendesse às transformações de uma sociedade burguesa incipiente, sendo estas teorias preconizadas pelos ideais da Revolução Francesa e do Iluminismo. Estes movimentos promoveram profundas mudanças sociais, as quais geraram importantes reflexões pedagógicas, culminando numa concepção de educação naturalista. De acordo com tal concepção pedagógica, nascemos desprovidos de tudo, portanto temos necessidade de assistência, e, assim, tudo o que não temos ao nascer e de que precisamos enquanto adultos pode nos ser dado pela educação (ROUSSEAU, 1973). Nesse mesmo período, desenvolveu-se a concepção de que a educação deveria priorizar os princípios morais, unindo liberdade à razão, orientando o homem no processo educativo e levando-o a agir com autonomia, porém, também, com obediência aos preceitos morais.

O século XIX foi um período caracterizado pelo avanço da ciência moderna, que provocou mudanças radicais na sociedade, suscitadas pelas ideias positivistas de Comte, o idealismo de Hegel e a teoria marxista ou materialismo histórico-dialético. Cada uma dessas ideias possui perspectivas diversas para a educação, que sob a influência das mudanças econômicas e científicas tentam efetivar-se pela criação de uma forma de pensamento e ação autônomos, o que expressa a confiança do homem no conhecimento científico (ARANHA, 1996).

Nesse contexto, a incorporação de novas ideias sobre o papel da escola promoveu um repensar enriquecedor acerca da educação, e, em especial, promoveu a discussão sobre o funcionamento da escola pública como meio de educação. Por conseguinte, o século XX configurou-se como período em que se apresenta mais fértil e propício para as reflexões acerca da educação, pois, diante das visões defendidas no período anterior, reacendem as discussões sobre o que é "melhor" para a educação e para a sociedade, solidificando, desta maneira, um conceito mais social para a educação do homem, a partir das ideias de Durkheim (apud GADOTTI, 1995), segundo as quais a sociedade é que dita os padrões de comportamento.

Cabe ressaltar que, nesse percurso histórico, nascem teorias e visões diversificadas, levando não só a educação, mas as ciências, a passarem por novos desafios e a enfrentarem a chamada "crise de paradigmas". Dessa maneira, surge e se desenvolve uma nova perspectiva educacional, a "Escola Nova", em oposição à perspectiva de educação tradicional. Essa nova concepção de educação teve uma notável influência, inicialmente, na Europa e nos Estados Unidos, no final do século XIX. Também chegou a desenvolver-se, em diferentes graus de intensidade, em países da América Latina, como: Argentina, Chile, Venezuela, Colômbia, Brasil. Salienta-se que cada país desenvolveu suas próprias particularidades de acordo com seus contextos culturais. 
Nessa nova forma de pensar sobre educação, reivindicava-se a significação, o valor e a dignidade da infância, valorando e fortalecendo os interesses espontâneos da criança, sua atividade, liberdade e autonomia. Cabe salientar que este termo foi utilizado com diferentes aceitações, tendo a finalidade de caracterizar o ensino em certos estabelecimentos educativos. De acordo com Lourenço Filho (1964), a expressão teve um sentido mais amplo diante da perspectiva na abordagem dos problemas da educação em geral, uma que vez que:

Não se refere a um só tipo de escola o sistema didático determinado, senão a todo um conjunto de princípios tendentes a rever as formas tradicionais do ensino. Esses princípios derivarão geralmente de uma nova compreensão das necessidades da infância, inspirada nas conclusões dos estudos que a biologia e a psicologia iniciavam por aquele então. Mas logo se ampliarão, chegando a se relacionar com os outros, muito numerosos, relativos às funções da escola frente às novas exigências da vida social. (LOURENÇO FILHO, 1964, p. 4, tradução nossa)

Dessa maneira, percebe-se o desenvolvimento de princípios gerais e comuns que caracterizariam todo o movimento reformador, numa perspectiva de multiplicidade de reflexões e experiências no âmbito educativo. Portanto, o processo reformador não se caracterizou por ser um movimento uniforme, visto que havia uma diversidade de correntes e realidades educativas compondo o movimento reformista. Exatamente nessas diferentes vertentes surgiram outras denominações afins do conceito de Escola Nova, que, por sua vez, colhem ou colocam o acento em uma ou outra dimensão dos planejamentos fundamentais plasmados neste, como aquelas da escola ativa, da escola moderna e da escola do trabalho, entre outras.

O movimento denominado "escola ativa" configurou-se mediante um importante e significativo princípio, segundo o qual a escola deve propiciar a atividade da criança, tendo como fundamento a crença de que a instituição deve tornar práticas as atividades e fazer o possível para desenvolver toda a atividade psicomotora própria da criança, a fim de centrar-se nos interesses desta e fazer mais eficazes o ensino e aprendizagem; em relação à denominação "escola moderna", o principal fundamento é a base científica e racional, que se inspira no aporte das ciências nascentes auxiliares da educação; numa terceira perspectiva, o movimento foi denominado "escola do trabalho", uma vez que parte da premissa de que a escola é uma sociedade viva, que deve preparar o aluno para a vida e familiarizá-lo com o meio social, e tem como principal finalidade a criação de algo novo em si, como os trabalhos manuais, visto que este, além de seu valor como formação profissional, tem um valor educativo (FOULQUIÉ, 1952).

Diante de todas essas tendências expostas, percebe-se que a Escola Nova foi um movimento amplo, complexo e contraditório, pois se constituiu com múltiplas e variadas apartações de experiências e autores de diferentes países. O movimento contou com importantes contribuições internacionais, tais como: Montessori, Ovide, John Dewey, Georg Kerschensteiner, Edouard Claparede, Adolphe Ferriére, Roger Cousinet e Célestin Freinet, entre outros.

É importante destacar que, no Brasil, as ideias desse movimento começaram a se desenvolver por volta de 1927, basicamente com o desenvolvimento de iniciativas como "O inquérito da instrução pública de 1926”, conduzido por Fernando de Azevedo, e a criação da 
Associação Brasileira de Educação (ABE) em 1927. Porém, num primeiro momento, não se chegou a implementar os ideais da Escola Nova devido ao descompasso entre esse ideário e a organização administrativa e de ensino preexistente nas escolas brasileiras. Essa reforma educacional pedagógica, cujo eixo da educação escolar seria o aluno, também recebeu várias denominações, como: "Escolanovismo" (NAGLE, 1976), "Escola Nova" (VIDAL, 2000) e "Escolas Novas" (CAMBI, 1999).

Foi no contexto educacional elucidado que se desenvolveram as concepções de Kerschensteiner acerca da educação. Suas obras externam, basicamente, preocupações com o processo educativo e a concepção de um modelo de escola formadora da sociedade. O educador idealizou modelos de ensino desenvolvendo estratégias e técnicas nas diferentes áreas de ensino, inclusive, na área de ciências. Nesse sentido, podem-se relacionar as ideias de Kerschensteiner a este espírito de reforma, porque ele descrevia a necessidade de se introduzirem novas teorias pedagógicas que proporcionassem um novo enfoque à escola tradicional existente.

\section{Concepções de Kerschensteiner acerca da educação}

Georg Kerschensteiner nasceu na Alemanha, na cidade de Munique, em 24 de julho de 1854, e estudou nas escolas de sua cidade natal até os doze anos, quando mudou-se para Freising, obtendo, assim, uma experiência própria da vida escolar daquela época. Ainda em Freising, cursou a carreira de magistério no seminário ou escola normal. Em 1876, foi nomeado professor de uma escola rural na Baviera, cargo que exerceu durante três anos, retomando, assim, suas experiências pedagógicas, que lhe seriam futuramente de muito valor (LUZURIAGA, 1961).

As propostas do pedagogo foram desenvolvidas no início do século $\mathrm{XX}$, as quais se juntaram a todo esse emaranhado de ideias desenvolvidas nos ideais da Escola Nova. Ele estruturou seus ideais basicamente no contexto educacional alemão, mediante uma perspectiva de "escola do trabalho", e pautando-se numa teoria da educação com base na preparação científica, com vista a desenvolvê-la mais tarde na prática. Para o educador, a formação humana não estava descolada do real, por isso, as suas principais obras discutem a escola e suas diferentes implicações existentes nela, uma vez que, em seu entendimento, a escola seria a base educacional de uma sociedade.

Kerschensteiner (1934, p. 8, tradução nossa) "buscava o homem de ação, que não deprecia em nenhum momento, ao procurar elementos científicos para ampliar e articular as suas experiências". Suas concepções apareceram no período em que o ensino estava caracterizado, basicamente, por duas tendências: humanista e realista. A partir da tendência realista, tem-se a inclusão dos conhecimentos científicos naturais nas escolas. Nesse sentido, o autor entra como opositor das ideias herbartianas, propondo discussões mais realistas. Entretanto, defende que a educação visa a aquisição (ou desenvolvimento) de valores educativos, sendo que o ensino possui valores comuns a todas as disciplinas e específico por disciplina.

Diante da preocupação em formar o homem de ação, o educador apontava, como valor educativo mais importante, a educação do pensamento lógico, sendo este comum a todas as matérias e/ou a todas as áreas do conhecimento, pois, para ele, esta forma de pensar se faz necessária no processo de aprendizagem. A partir destas colocações, percebem-se algumas características do movimento reformador no trabalho do pedagogo. Sua atuação junto aos demais 
representantes da Escola Nova tinha como principal objetivo mudar o rumo da educação tradicional, intelectualista e livresca, dando um sentido vivo e ativo ao conhecimento. O cerne da nova educação era a preocupação de adaptar, de diferenciar, de individualizar; e foi, a partir desta proposição, que o autor colocou em prática o seu modelo de "escola do trabalho" em todos os níveis de ensino, nas escolas de Munique entre 1910 e 1914 (LUZURIAGA, 1961).

No que tange à sua prática educativa, o pedagogo assumiu duas premissas fundamentais, que foram decisivas em todo seu trabalho: o processo educativo implica liberdade; a verdadeira educação exige, de antemão, o conhecimento exato e profundo dos educandos (LUZURIAGA, 1961). Estas colocações do educador nos ajudam a entender, de uma forma visível, suas preocupações acerca da formação do homem; e, portanto, seu trabalho tinha, fundamentalmente, a finalidade de renovar as escolas, pois, só assim, poderia derrubar todo o aparato pedagógico tradicional.

Dessa maneira, para o autor, a educação tinha a finalidade de, mediante o trabalho, levar a moralização da profissão e, assim, chegar à moralização da sociedade (HUBERT, 1952). Esse tipo de prática era entendido, por Kerschensteiner, como ideal, pois, só assim, a escola cumpre o seu papel dentro da sociedade, uma vez que o trabalho realizado dentro dessa escola cria atitudes significativas para a formação do homem. A partir de tais posicionamentos, notase sua preocupação com a formação das crianças e dos jovens, pois ele acreditava que a escola deveria substituir a aquisição metódica e o ensino mecanicista, falsamente científico, por conhecimentos oriundos da vida, do cotidiano dos alunos. A escola ideal é a escola que consegue fazer relação do ensino com o seu meio social, pois esta relação é essencial para não acomodar o ensino a uma realidade social inativa, como acontece com as escolas livrescas que se tornam incapazes de formar alunos críticos e aptos para lutarem na "transformação do futuro".

Comprometido com a formação profissional e de valores morais e cívicos que pudessem formar o homem capaz de se desenvolver dentro da sociedade, Kerschensteiner ressalta a importância da valorização do conhecimento do cotidiano da sociedade no processo de aprendizagem. Dessa maneira, ele entendia que a "escola pública" tinha a função de auxiliar o indivíduo no preparo profissional (LUZURIAGA, 1961).

Nessa mesma tônica, o educador adverte que, ao estabelecerem o vínculo da ação pedagógica com a realidade cotidiana, os educadores estarão atingindo o objetivo da pedagogia prática, pois a finalidade maior da educação é proporcionar, às crianças, a formação do espírito e crescimento pessoal e social, podendo, assim, elevá-los a um máximo de humanidade, preparando-as para agirem em prol de uma sociedade melhor (KERCHENSTEINER, 1934).

De modo geral, o trabalho manual determinava as reformas propostas por Kerschensteiner (1932), mas que esta escola não deveria ser totalmente manual, no interior do sistema escolar. A esse respeito, o pedagogo enfatizava que o ensino é paralítico sempre que não coincidir com a prática e com o costume, pois, só mediante o trabalho e pelo trabalho realmente prático em uma organização da escola ou da vida pública, se poderia formar o homem. É interessante perceber como ele faz um diagnóstico geral do processo de ensino, descrevendo de que maneira o trabalho, como parte prática do ensino, pode ajudar na formação de um indivíduo. Fazendo, ainda, a ressalva de que indicações formativas profissionalizantes são dirigidas aos jovens; dessa forma, recomenda as escolas de trabalho, ou seja, um sistema corretivo típico das instituições escolares voltadas para a formação do trabalhador por meio do trabalho. 
Finalmente, dentro do que foi exposto, levantamos a importância de se analisarem as seguintes questões: quais as concepções sobre educação e ensino, enfatizando o ensino de ciências, presentes nas obras de Georg Kerschensteiner? Já que, ao se realizar um levantamento bibliográfico sobre os estudos e investigações, notou-se que há uma imensa carência de análises a respeito do pensamento deste clássico.

\section{O olhar sobre o ensino de ciências}

Chassot (2004) aponta que o século XIX foi o período no qual a ciência se consolidou, proporcionando, na transição entre este e o século XX, avanços significativos que influenciaram a maneira de viver do homem contemporâneo. Mediante o desenvolvimento promovido pelas ciências naturais, estas foram adquirindo importância na formação e preparo do homem para viver nessa sociedade que se depara no bojo das mudanças ocorridas, na qual a escola, enquanto instituição formal de ensino, também está inserida.

O ensino de ciências adentrou o processo educativo no limiar do século XIX, em alguns países europeus, como reflexo do desenvolvimento das Ciências Naturais, mediante resistências instauradas pela forma, até então vigente, de se compreender o mundo natural e a tradição religiosa. Conforme esta visão, nos estabelecimentos de ensino, o estudo de línguas como grego e latim era a ginástica intelectual que proporcionava, aos alunos, o uso e o domínio do pensamento (KERSCHENSTEINER, 1928). Foi diante desse contexto que, aos poucos, o ensino de ciências foi se integrando ao currículo escolar, consubstanciado pela maneira de fazer ciência e a visão mecanicista da realidade. De acordo com as concepções mencionadas, correntes pedagógicas do referido período preconizavam que:

[...] as Ciências Naturais são o meio graças ao qual todas as forças da natureza tornam-se recursos à nossa disposição, desde que compreendamos seus fatos e suas leis. O caminho que leva à dominação da Terra passa pela paciente observação, experimentação e estudo. [...] o mundo existe como alvo para a conquista do homem e os instrumentos para isto são a ciência e o processo educativo. (GILES, 1987, p. 244)

De acordo com essa visão, o processo educativo se pautava nas etapas do método indutivo para atingir os seus objetivos na formação do homem, no qual se estruturava o ensino de ciências. Com o auxílio desse método, a mente do aluno, a partir de vivências de experiências, as ordena e interpreta-as com a ajuda do professor, e caminha, gradativamente, para sistemas de generalizações ou "verdades" (GILES, 1987).

Outra característica fortemente presente no início do século XX era a de um ensino de ciências de caráter utilitarista e descritivo. Kerschensteiner (1928) salientava que a introdução das ciências naturais nos currículos das escolas primárias e secundárias alemãs se deve, em grande parte, a essa característica utilitarista, que, segundo o autor, estava presente nos livros didáticos adotados.

Em termos comparativos, no mesmo período no Brasil, o ensino das ciências naturais encontrava-se incipiente, não sendo ainda estabelecido de forma efetiva nos currículos escolares dos ensinos secundários e primários, embora, desde a criação do Colégio Pedro II, em 
Bueno, G. M. G. B.; Farias, S. A.; Ferreira, L. H.

1837, as ciências já fizessem parte do currículo do ensino secundário, e isto é reflexo da ausência de um sistema de ensino bem estruturado. Todavia, é possível inferir sobre algumas características que apresentava o ensino de ciências, como: ausência de atividades experimentais e ensino fortemente teórico (livresco), utilitarista e descritivo. Estas podem ser verificadas em estudos que se propõem a uma análise histórica do ensino, como no exemplo de Chassot (1996), e, também, na análise histórica de livros didáticos, como nos exemplos de Lorenz (1986) e Mortimer (1988).

Para Kerschensteiner (1928), a tendência tradicional do ensino em nada iria contribuir para o ensino das ciências naturais, que pudesse desenvolver valores educativos, uma vez que:

[...] a educação do pensamento lógico é e será em todos os tempos a finalidade essencial, não das escolas secundarias como organização educativa, mas do ensino secundário como parte principal dessa organização, seria improcedente, caso isso se demonstrasse ir pondo fora de uso tal instrumento. (KERSCHENSTEINER, 1928, p. 27)

Conforme mencionado na seção anterior, a educação do pensamento lógico era o valor educativo mais importante, e, portanto, deveria ser inerente a todas as disciplinas escolares, ressaltando que o papel fundamental da escola é a educação do pensamento, pois, dessa maneira, o homem poderia buscar, de forma cuidadosa e científica, a solução mais adequada para situações que lhe apresentem a profissão, a vida e as relações.

Tal entendimento assinalava que a aprendizagem das ciências naturais seria um componente essencial para o desenvolvimento do intelecto, pois, para compreender a mesma, não se faz necessário ter boa memória, visto que a essência da instrução lógica não consiste precisamente na assimilação de um conjunto de regras e de leis, mas em desenvolver processos mentais racionais que proporcionem a aplicação das leis científicas naturais aos problemas de investigação, do conhecimento, da técnica da vida prática e da compreensão dos fenômenos. Nessa perspectiva, salvo algumas limitações, é possível identificar que as concepções de Kerschensteiner guardam proximidade com os objetivos educacionais propostos para o Ensino de Ciências numa abordagem construtivista (DRIVER et al., 1999; HARRES, 2008; SCHNETZLER, 2010).

No contexto educativo em que o pedagogo escreveu sua obra - que trata das suas reflexões sobre o ensino de ciências nas escolas primárias e secundárias de seu país - intitulada "Essência e valor do ensino scientifico-natural" e publicada na Alemanha em 1913, o autor informa que o ensino das "línguas mortas", latim e grego, desfrutava do status no preparo da elite intelectual. Portanto, ao apresentar seus argumentos sobre a essência do valor do ensino das ciências naturais, tece comparações com a forma de ensinar as referidas disciplinas (KERSCHENSTEINER, 1928).

No Brasil, estudos relacionados ao currículo das ciências e história da educação mostram que a característica acima mencionada perdurou até a década de 1950, uma vez que as disciplinas científicas tinham carga horária menor que as de humanidades. O ensino do latim era preponderante nos currículos do ensino secundário, enquanto, no currículo do ensino primário, as ciências naturais passaram a constar de forma efetiva a partir da década de 1970, quando foi promulgada a Lei 5.692/71, a qual reestruturou os níveis de ensino e tornou o 
ensino de ciências obrigatório nas oito séries do $1^{\circ}$ grau (KRASILCHIK, 1987; LOPES, 1998; ROMANELLI, 2007).

A preocupação com a reduzida carga horária das disciplinas científicas nas escolas públicas alemães, no início do século XX, foi manifestada por Kerschensteiner (1928) em sua obra, uma vez que ele critica o tempo de aula necessário para desenvolver atividades que fossem relevantes para o desenvolvimento do pensamento lógico, e coloca este como um dos problemas a serem enfrentados pelo ensino das ciências naturais.

No capítulo III de sua obra, denominado "As sciencias naturaes e a educação intelectual", ele propôs investigar se existe possibilidade de o ensino destas ciências seguir o mesmo processo de estudo de uma tradução (línguas mortas ou modernas), nos moldes que conduza ao desenvolvimento de habilidades de raciocinar logicamente (KERSCHENSTEINER, 1928). Isto pode ser verificado no primeiro parágrafo do capítulo:

[...] pretendemos determinar seguidamente o apoio que este ensino proporciona aos demais factores da disciplina intellectual, pelo habito da formação de conceitos fixos e da comprehensão unívoca por meio da palavra ou de algum outro sinal. [...] esta concepção unívoca da Idea é uma condição previa indispensavel para lograr bons resultados no processo logico de pensar. (KERSCHENSTEINER, 1928, p. 65)

Com a finalidade de apresentar suas concepções acerca do ensino de ciências, o autor buscou fazê-lo por meio de exemplos de atividades em Química, Física e Botânica. Algumas destas exemplificações vão ao encontro do que ele acreditava ser o melhor caminho para ensinar ciências nas escolas, e outros vão de encontro às suas concepções. Estes exemplos foram buscados nos materiais didáticos da época, os quais o autor foi enfático em afirmar que carecem de atividades que proporcionem o desenvolvimento do pensamento lógico do aluno, sobretudo no que concerne ao ensino da Física.

Numa atividade relacionada ao ensino de Química, o autor descreveu um experimento no qual um estudante faz considerações sobre um fenômeno que ocorre à medida que um pó vermelho entra em contato com uma lâmina de cobre polida, sendo friccionado com a mesma. Várias questões são levantadas a partir da constatação inicial de manchas de cor negra na superfície da placa, que, com o passar do tempo, vão modificando-se em manchas de uma brilhante cor branca prateada. Diante desse fato, o autor propôs que o aluno faria suposições, observando as variáveis que possam estar influenciando na ocorrência do fenômeno, como as que seguem:

[...] Por que motivo o pó vermelho não produz manchas vermelhas e sim pretas? [...] É possível que o calor produzido pela fricção chegue a converter o pó vermelho em outro de cor negra? Por que se transformam depois em manchas negras em outras brilhantes e prateadas? (KERSCHENSTEINER, 1928, p. 71)

A partir de suas conjecturas, o aluno continua a atividade buscando realizar o mesmo procedimento com outros materiais que propiciem a verificação das suas suposições, e, com 
isso, tirando suas próprias conclusões. Ele vai testando as possibilidades e observando, buscando uma explicação para o fenômeno que seja coerente, e relacionando suas observações com o conhecimento teórico até que esta explicação possa ser estabelecida.

Para Kerschensteiner (1928), esta maneira de ensinar ciências suscitando problemas conduz o aluno a desenvolver o hábito do pensar lógico, e impõe que o aluno busque o sentido de relação entre os fenômenos, sendo obrigado a formular perguntas concretas de acordo com suas conjecturas e se valendo da experimentação para ajudá-lo a comprovar ou negar suas suposições.

Em outro exemplo de atividade analisado na obra do teórico Kerschensteiner (1928), acerca do ensino da ciência Física, o autor critica uma sequência de passos para comparar o ângulo de incidência com o de reflexão. $\mathrm{Na}$ proposta de atividade, estipula-se o tempo que será gasto, os instrumentos a serem utilizados, bem como os passos a serem seguidos, como podem ser verificados em alguns trechos:

[...] Fixe-se convenientemente o papel na prancheta de desenho. Tracese a recta $g$ (veja-se a figura). Coloque-se de tal forma o espelho sobre o papel que a beirada inferior da superfície estanhada coincida com a recta g. Fixe-se a agulha $B$ junto do espelho e a agulha $A$ collocada a 12 cms. de distancia da primeira, de forma a ficarem exactamente perpendiculares á prancheta. Fechando um dos olhos, ponha-se a cabeça em tal posição que a agulha $A$ occute a $B$, e, sem mover a cabeça, colloquem-se duas agulhas, $C$ nas proximidades do espelho $D$ a uns $12 \mathrm{cms}$. de distância da primeira; [...]. (KERSCHENSTEINER, 1928, p. 7778 , grifos do autor)

Para o teórico, atividades experimentais como as deste exemplo não favorecem o desenvolvimento intelectual. Ele tece críticas a respeito do motivo pelo qual os roteiros de atividades experimentais são presentes nos livros didáticos, apontando que:

[...] o escasso tempo que se concede e se pode conceder á instrucção scientifico-natural nos centros de segundo ensino contribuíram bastante para que estes exercícios não se tenham desenvolvido além de um sector determinado de mera instrucção, o que não pode ser evitado, a principio, na iniciação ás diversas leis physicas, especialmente se se tiver em conta a inexperiência dos alumnos no tocante aos methodos de investigação. (KERSCHENSTEINER, 1928, p. 82)

Porém, acredita que os exercícios escolares e, mesmo, as demonstrações realizadas pelos professores não deveriam se orientar para a descoberta da lei. Ele aponta que o primeiro é difícil e o segundo não é atraente para o aluno. Sendo assim, para o autor, as atividades que proporcionam o exercício de pensar seriam aquelas que estão ancoradas no "desenvolvimento paulatino das próprias manipulações defeituosas e observações falsas, no descobrimento dos erros, por meio da comparação com as anteriores observações estabelecidas sobre a base das reflexões próprias" (KERSCHENSTEINER, 1928, p. 78). 
A partir de dois exemplos de atividades expostos por Kerschensteiner (1928) e apresentados neste trabalho sucintamente, pode-se inferir que, no início do século XX, nas escolas alemãs, a utilização da experimentação no ensino de ciências tinha uma abordagem proposta pelos livros didáticos de ciências. Em relação ao experimento de Física, o teórico assinala que era o primeiro dos 25 exercícios de "Óptica" presentes em um livro da época.

Conforme mencionado, Kerschensteiner (1928) pauta sua pedagogia na prática dos métodos ativos de ensino, afirmando que é pela experiência que, verdadeiramente, nos instruímos, e que só o que é vivido por nós incorpora-se intimamente e se torna nossa substância intelectual, impulsionando nossa atividade de pensamento. Portanto seria de esperar que a experimentação no ensino de ciências fosse parte integrante do currículo escolar para o pedagogo, uma vez que se opõe ao ensino livresco.

Porém, o autor enfatizava a utilização da experimentação, não com a finalidade de provar e/ou chegar à dedução de uma lei, mas de tornar o conhecimento científico compreensível por meio de sua aplicação, utilizando-o para explicar fenômenos e solucionar problemas próprios do cotidiano dos alunos. Para tanto, utiliza-se da interrogação, observação, indução e dedução, como no exemplo apresentado sobre a atividade de Química, o qual acreditava ser um bom exemplo para desenvolver a educação intelectual.

Segundo o pedagogo, a observação não é uma mera percepção do fenômeno, e ressalta, ainda, que, dentre os valores educativos, o desenvolvimento da capacidade de observação está diretamente relacionado ao ensino mais que qualquer outro valor, podendo este ser efetivamente desenvolvido pelo ensino das ciências naturais. Assim, também preconizava que as ciências experimentais desenvolvem a aptidão de observar melhor que qualquer outra área do ensino (KERSCHENSTEINER, 1928).

$\mathrm{Na}$ concepção do autor, a atividade de observar pressupõe um propósito de observação que nos faça tomar consciência a ponto de ocasionar a formulação de perguntas, de questionamentos, e esta decorre de experiências e conhecimentos acumulados anteriormente de forma voluntária ou involuntária. Desta maneira, mais uma vez, as ideias de Kerchensteiner se opõem ao positivismo, uma vez que associa a capacidade de observar com conhecimentos e experiências acumulados anteriormente, ou seja, como Hodson (1982) afirma em seus estudos relacionados ao método científico no ensino de ciências, as observações não são imparciais, pois são dependentes de teorias.

A atividade de observar pode ser dirigida com o propósito de fixar relações simples e formais, com o intuito de estabelecer relações especiais, qualidades de cor e manifestação de movimentos, entre outras. Por conseguinte, ampliamos num determinado sentido o nosso mundo de representações. $\mathrm{O}$ autor ressalta que, quando nossas observações são dirigidas a dependências causais, estas vêm favorecer nosso mundo de representações e conceitos promovendo a transformação de nossas idrias, pois toda observação supõe "[...] uma classificação das percepções e um estabelecimento de relações entre as imagens produzidas, isto é, exige uma atividade mental de caráter reflexivo" (KERSCHENSTEINER, 1928, p. 111).

Assim, é importante salientar a proximidade das ideias do educador com estratégias de ensino atuais relacionadas à área de Ensino de Ciências, denominadas como problematizadoras, como, por exemplo, o método investigativo. Em linhas gerais, em tal abordagem de ensino, o estudante é colocado frente a uma situação problema, a qual requer que ele elabore hipóteses que possam explicar tal situação. Em relação à crítica que Kerschensteiner (1928) 
faz ao segundo exemplo apresentado, no que tange ao roteiro da atividade experimental, o método investigativo também se contrapõe a tal prática (FERREIRA; HARTWIG; OLIVEIRA, 2010; KASSEBOEHMER, 2011).

As concepções e preocupações do pedagogo, no início do século XX, acerca do ensino de ciências nos níveis primário e secundário de ensino, ainda são atuais, em alguns aspectos, no ensino de ciências no contexto brasileiro, visto que muitas mudanças e avanços aconteceram nessa área por influências das relações de trabalhos, modos de produção e avanços tecnológicos estabelecidos mediante os modelos econômicos de cada período. Portanto, os fins educacionais são dinâmicos e vão sofrendo mudanças diante dos aspectos mencionados, refletindo no currículo escolar, nos materiais didáticos e nos métodos de ensino, entre outros.

Krasilchik (1987), num estudo sobre a evolução do ensino de ciências no período de 1950 a 1985, aponta que as principais características do ensino eram: teórico, livresco, memorístico, estimulando a passividade; e que várias mudanças eram almejadas na década de 1950, entre elas, as mudanças curriculares que incluíam a substituição dos métodos expositivos pelos chamados métodos ativos, dentre os quais tinham preponderância as aulas experimentais. Foi possível verificar que as principais características do ensino das ciências apresentadas na análise de Krasilchik (1987) e as manifestadas por Kerschensteiner guardam proximidade, pois, embora as ideias do pedagogo tenham sido concebidas em um contexto sócio-econômico e educativo diferentes da realidade brasileira (Alemanha no final do século XIX), a proposta educacional do pedagogo para o ensino de ciências enfoca processos ativos de aprendizagem em que o aluno é sujeito ativo nesse processo. Como pode ser observado no Quadro 1, para o pedagogo, o principal objetivo do ensino era educar o pensamento lógico, e, como um objetivo específico, desenvolver a capacidade de observação por meio de atividades experimentais. No Brasil, estes aspectos configuram-se somente a partir da década de 1970, embora, como apontam Ferreira e Hartwing (2004), o início do ensino de Química nas escolas secundárias tenha ocorrido no Brasil em 1880. Somente noventa anos depois, é que os objetivos parecem estar concatenados com os idealizados no início do século XX pelo pedagogo.

Quadro 1. Comparações entre os principais aspectos das concepções defendidas por Kerschensteiner e as encontrados no contexto brasileiro

\begin{tabular}{|l|l|l|}
\hline Aspectos principais & $\begin{array}{l}\text { Concepções de Kerschensteiner } \\
(1928)\end{array}$ & $\begin{array}{l}\text { Cenário brasileiro a partir da segunda metade } \\
\text { do século XX (KRASILCHIK, 1987) }\end{array}$ \\
\hline $\begin{array}{l}\text { Objetivo do ensino } \\
\text { das ciências }\end{array}$ & $\begin{array}{l}\text { Educar o pensamento lógico e } \\
\text { desenvolver a capacidade de } \\
\text { observação. }\end{array}$ & $\begin{array}{l}\text { Anos 50: transmitir informações atualizadas; } \\
\text { Anos 60: vivenciar o método científico; } \\
\text { Anos 70: desenvolver a capacidade de pensar } \\
\text { logicamente e criticamente. } \\
\text { Anos 80: refletir sobre as implicações sociais } \\
\text { do desenvolvimento científico e tecnológico. }\end{array}$ \\
\hline $\begin{array}{l}\text { Metodologia } \\
\text { recomendada }\end{array}$ & $\begin{array}{l}\text { Aulas experimentais mediante } \\
\text { discussões, pesquisa na resolução } \\
\text { de problemas, de preferência } \\
\text { voltados para o cotidiano do aluno. }\end{array}$ & $\begin{array}{l}\text { Anos 50: laboratório; } \\
\text { Anos 60: laboratório mais discussões de } \\
\text { pesquisa; } \\
\text { Anos 70 e 80: jogos e simulações; resolução de } \\
\text { problemas. }\end{array}$ \\
\hline
\end{tabular}


Em relação à educação de uma maneira mais ampla, as concepções do educador também se aproximam de entendimentos atuais presentes nas orientações oficiais, uma vez que ele defende que a ação pedagógica necessita estabelecer vínculo com a realidade cotidiana. Nesse sentido, as Orientações Curriculares para o Ensino Médio, no âmbito das Ciências da Natureza, Matemática e suas Tecnologia (BRASIL, 2006), defendem uma abordagem de temas sociais, com a necessária articulação entre a proposta pedagógica e as situações reais de ensino.

Entretanto, atualmente, pesquisas no campo educacional, mesmo experimentando uma fase de grande desenvolvimento, pouca influência exerceram sobre as crenças dos professores de ciências que atuam na Educação Básica. As concepções que professores de ciências manifestam sobre como ensinar na sua prática docente cotidiana não apresentam significativas mudanças, e o processo de construção do conhecimento escolar ainda mostra-se arraigado no dia a dia das salas de aula, conforme relata Manfredo (2003), que realizou uma pesquisa com professores de ciências de $5^{\mathrm{a}}$ a $8^{\mathrm{a}}$ séries do Ensino Fundamental no município de Belém, PA. A esse respeito, Praia, Cachapuz e Gil-Pérez (2002), em uma proposta de reorientação epistemológica na Educação em Ciências, a partir de um levantamento de outros estudos, destacam que professores de ciências constroem imagens de ciências marcadas por visões de índole empirista/indutivista. Tais concepções são as mesmas que Kerschensteiner (1928) critica em sua obra.

Outro aspecto em que as concepções do pedagogo assemelham-se às concepções atuais corresponde à experimentação no ensino de ciências. Kerschensteiner defende a presença da experimentação no currículo de ciências, porém aponta que esta atividade deve ser utilizada por meio da investigação de situações-problema, o que assemelha-se com a investigação proposta por Hofstein e Lunetta (2004), Ferreira, Hartwig e Oliveira (2010), na qual a atividade experimental implica: fazer observações, propor perguntas e pesquisar em livros e outras fontes de informação, exigindo, desta maneira, o uso do pensamento crítico e lógico.

\section{Considerações finais}

Percebe-se que a proposta educacional do autor enfatiza a construção de uma nova escola, pois ele acreditava que, só assim, a educação poder-se-ia se tornar melhor. Nesse contexto, ele vê a escola como algo definitivo na formação do novo ser.

No contexto formativo dessa escola do trabalho, para o pensador, a mesma tinha um espírito de formação, o que o levou a introduzir o trabalho na escola para que esta exercesse realmente uma influência educativa.

O autor descreve, em toda a sua proposta educacional, a importância de se começar a instrução ainda na infância, e que esta deve continuar tanto na adolescência quanto na fase adulta. Assim, discute diferentes formas de ensino e adverte que, ao estabelecerem o vínculo da ação pedagógica com a realidade cotidiana, os educadores estarão atingindo o objetivo da pedagogia prática, pois, para ele, a finalidade maior da educação é proporcionar, às crianças, a formação do espírito e crescimento pessoal e social.

Para o autor, a educação está ligada com a cultura e, por isso, as suas principais preocupações descrevem a criação de novas formas de ensino. Assim, ele descreve a prática como algo fundamental no processo de ensino de ciências, criando uma nova realidade social. Nesse sentido, a escola proposta pelo autor tinha como princípio básico o trabalho, determi- 
Bueno, G. M. G. B.; Farias, S. A.; Ferreira, L. H.

nando, assim, o processo educativo de uma escola ativa, que forma o aluno por meio do trabalho, pois Kerschensteiner acreditava que, desta forma, o indivíduo poderia conseguir a autodisciplina, sendo a atividade física considerada uma condição necessária e significativa dentro do processo de transformação do futuro homem.

Suas ideias acerca da experimentação no ensino de ciências, nos níveis primário e secundário, ainda são atuais em alguns aspectos no contexto brasileiro, visto que muitas mudanças e avanços aconteceram nessa área por influências das relações de trabalho, modos de produção e avanços tecnológicos, estabelecidos mediante os modelos econômicos presentes na sociedade em cada período. Entendendo que os fins educacionais são dinâmicos e sofrem mudanças diante dos aspectos mencionados, é importante refletir sobre o currículo escolar, os materiais didáticos e os métodos de ensino, entre outros.

Contudo, o autor defende que a escola é um processo que se inicia na infância e se conclui na fase adulta. Nesse sentido, vê a escola como um lugar onde o processo de instrução é permanente e promove a formação constante do ser em formação.

\section{Referências}

ARANHA, M. História da educação. São Paulo: Moderna, 1996.

BRASIL. Secretaria de Educação Básica. Orientações curriculares para o ensino médio: ciências da natureza, matemática e suas tecnologias. Brasília, 2006. v. 2. Disponível em: $<$ http://portal.mec.gov.br/seb/arquivos/pdf/book_volume_02_internet.pdf >. Acesso em: 30 dez. 2011.

CAMBI, F. História da pedagogia. São Paulo: Ed. da Unesp, 1999.

CHANTÊAU, J. Os grandes pedagogistas. São Paulo: Nacional, 1978.

CHASSOT, A. A ciência através dos tempos. 2. ed. São Paulo: Moderna, 2004.

CHASSOT, A. I. Uma história da educação química brasileira: sobre seu início discutível apenas a partir dos conquistadores. Episteme, Porto Alegre, v. 1, n. 2, p. 129-145, 1996.

COUSINET, R. A educação nova. São Paulo: Nacional, 1959.

DI GIORGI, C. Escola nova. São Paulo: Ática, 1986.

DRIVER, R. et. al. Construindo conhecimento científico na sala de aula. Química Nova na Escola, São Paulo, n. 9, p. 31-40, maio 1999.

FERREIRA, L. H.; HARTWIG, D. R. GT2 experimentação. In: ENCONTRO PAULISTA DE PESQUISA EM ENSINO DE QUÍMICA, 1., 2004. Disponível em: <gpquae.iqm.unicamp.br/ EPPEQ.pdf>. Acesso em: 10 set. 2006.

FERREIRA, L. H.; HARTWIG, D. R.; OLIVEIRA, R. C. Ensino experimental de química: uma abordagem investigativa contextualizada. Química Nova na Escola, São Paulo, v. 32, n. 2, p. 101-106, 2010. 
FERRIÉRE, A. Transformemos la escuela. Barcelona: Fraternidad Internacional de Educación, 1929.

FOULQUIÉ, P. As escolas novas. São Paulo: Nacional, 1952.

GADOTTI, M. Historia das idéias pedagógicas. 3. ed. São Paulo: Ática, 1995.

GILES, T. R. História da educação. São Paulo: EPU, 1987.

HARRES, J. B. S. Natureza da ciência e implicações para a educação científica. In: MORAES, R. (Org.). Construtivismo e ensino de ciências: reflexões epistemológicas e metodológicas. 3. ed. Porto Alegre: EDIPUCRS, 2008. p. 37-68.

HODSON, D. Experiments in science and science teaching. Educational Philosophy and Theory, Randwick, n. 20, n. 2, p. 53-66, 1988. (Tradução de Paulo A. Porto).

. Is there a scientific method? Education in Chemistry, London, v. 19, n. 4, p. 112-116, 1982.

HOFSTEIN, A.; LUNETTA, V. N. The laboratory in science education: foundations for the twenty-first century. Science Education, Salem, v. 88, n. 1, p. 28-54, 2004.

HUBERT, R. Historia de la pedagogia. Buenos Aires: Kapelusz, 1952.

KASSEBOEHMER, A. C. O método investigativo em aulas teóricas de química: estudo das condições da formação do espírito científico. 2011. 180p. Tese (Doutorado em Ciências) - Centro de Ciências Exatas e de Tecnologia, Universidade Federal de São Carlos, São Carlos, 2011.

KERSCHENSTEINER, G. El problema de la educación pública. Madrid: San Marcos, 1932.

1928.

Essência e valor do ensino scientifico-natural. 3. ed. Rio de Janeiro: Athena,

La educación cívica. Buenos Aires: Labor, 1934.

KRASILCHIK, M. O professor e o currículo das ciências. São Paulo: EPU; EDUSP, 1987.

LOPES, A. R. C. A disciplina química: currículo, epistemologia e história. Episteme, Porto Alegre, v. 3, n. 5, p. 119-142, 1998.

LORENZ, K. M. Os livros didáticos e o ensino de ciências na escola secundária brasileira no século XIX. Ciência e Cultura, São Paulo, v. 38, n. 3, p. 426-435, 1986.

LOURENÇO FILHO, M. B. Introducción al estudio estudio de la escuela nueva. São Paulo: Melhoramentos, 1964.

LUZURIAGA, L. Ideas pedagógicas del siglo XX. Buenos Aires: Losada, 1961. 
Bueno, G. M. G. B.; Farias, S. A.; Ferreira, L. H.

MANFREDO, E. C. G. Tendências da prática do professor de ciências: um olhar para o ensino público fundamental do município de Belém. In: I CONGRESSO BRASILEIRO DE FORMAÇÃO DE PROFESSORES, 1., 2003, Curitiba. Anais... Curitiba: Editora da Faculdade Kennedy, 2003. v. 1. p. 1-35.

MORTIMER, E. F. A evolução dos livros didáticos de química destinados ao ensino secundário. Em Aberto, Brasília, v. 7, n. 40, p. 24-41, 1988.

MORTIMER, E. F.; SCOTT, P. Atividade discursiva nas salas de aulas de ciências: uma ferramenta sociocultural para analisar e planejar o ensino. Investigações em Ensino de Ciências, Porto Alegre, v. 7, n. 3, p. 283-306, 2002. Disponível em: <http://

www.if.ufrgs.br/ienci/artigos/Artigo_ID94/v7_n3_a2002.pdf >. Acesso em: 27 mar. 2009.

NAGLE, J. Educação e sociedade na primeira República. São Paulo: EPU, 1974.

PENHA, L. D. Filosofia da educação nova. São Paulo: Nacional, 1951.

PRAIA, J. F.; CACHAPUZ, A. F. C.; GIL-PÉREZ, D. Problema, teoria e observação em ciência: para uma reorientação epistemológica da educação em ciência. Ciência \&

Educação, Bauru, v. 8, n. 1, p. 127-145, 2002.

ROMANELLI, O. O. História da educação no Brasil: (1930/1973). 31. ed. Petrópolis: Vozes, 2007.

ROUSSEAU, J. J. Emilio ou da educação: (1712-1778). 2. ed. São Paulo: Difusão Européia do Livro, 1973. (Clássicos Garnier).

SCHNETZLER, R. P. Apontamentos sobre a história do ensino de química no Brasil. In: SANTOS, W. L. P.; MALDANER, O. A. (Org.). Ensino de química em foco. Ijuí: Ed. Unijuí, 2010. p. 51-75.

VIDAL, D. G. (Org.). Na batalha da educação: correspondência entre Anísio Teixeira e Fernando de Azevedo (1929-1971). Bragança Paulista: EDUSF; São Paulo: Instituto de Estudos Brasileiros, 2000.

Artigo recebido em 10/10/2011. Aceito em 14/03/2012. 